\title{
A CONSTITUIÇÃo dA IDENTIDAdE METROSSEXUAL PELO CONSUMO ${ }^{1}$
}

\section{METROSEXUAL IDENTITY CONSTITUTION BY CONSUMPTION}

\author{
Michele Araujo da Costa Oliveira² \\ André Luiz Maranhão de Souza Leão ${ }^{3}$
}

\begin{abstract}
RESUMO: Cada vez mais a questão da identidade tem sido debatida. As identidades que eram vistas como sólidas e fixas, hoje, com o "sujeito pós-moderno", começam a se fragmentar. Fala-se, assim, em identidade cultural, ou seja, o sujeito construído a partir do cultural e do ambiente que ocupa. A questão do gênero é uma dessas construções. Se antes se pensava a identidade de gênero como algo biológico, hoje é observado como construção cultural. Neste aspecto, algumas abordagens sobre gênero focam essa construção da identidade e a sua relação com o consumo, assim, o consumo passa a desempenhar papel central na construção das identidades. Tendo em vista esse novo panorama em relação à identidade observamos que, dentre dessas novas possibilidades de identidade de gênero, surge a identidade metrossexual. O presente estudo teve por objetivo compreender a construção da identidade metrossexual por meio do consumo. Para tal, realizamos uma pesquisa qualitativa por meio de entrevistas em profundidade com sujeitos identificados pelo seu comportamento de consumo metrossexual, às quais foram submetidas a uma análise de discurso que apontou para categorias identitárias destes sujeitos. O artigo apresenta e discute como o comportamento de consumo se demonstra como elemento constituinte desta identidade pós-moderna.
\end{abstract}

PALAVRAS-CHAVE: consumo metrossexual, identidades pós-modernas, pesquisa qualitativa.

ABSTRACT: Increasingly, the question of identity has been debated. Former seen as solid and fixed, today, with the "postmodern subject", identities begin to fragment. It is spoken, therefore, of cultural identity, that is, the subject constructed from cultural and environment s/he occupies. The gender issue is one of those buildings. If previously gender identity was thought as something biological, today it is seen as a cultural construct. In this respect, some approaches on gender construction focus on its relation to consumption, as consumption passes to play a central role in the construction of identities. Given this new landscape relative to identity we observe that among these new possibilities of gender identity, there is the metrosexual identity. This study aimed to understand the metrosexual identity construction through consumption. To this, we conducted a qualitative research through in-depth interviews with individuals identified by their metrosexual consumption behavior. Such interviews were submitted to discourse analyses, which indicate those subject's identity categories. The paper presents and discusses how consumption is shown as a constituent element of postmodern identity.

KEYWORDS: metrosexual consumption, postmodern identities, qualitative research.

\footnotetext{
${ }^{1}$ Artigo Recebido em 05.04.2010. Revisado por pares em 26.07.2011. Recomendado em 27.08.2011 por Leomar dos Santos Editor. Publicado em 15.09.2011.

Organização Responsável pelo periódico: Universidade regional de Blumenau - FURB - www.furb.br/rn

${ }^{2}$ Associação Paraibana de Ensino Renovado - ASPER - $\underline{\text { michelecost@gmail.com }}$

${ }^{3}$ Universidade Federal de Pernambuco- UFPE - andre.leao@pq.cnpq.br
} 


\section{INTRODUÇÃO}

O século XXI tem trazido consigo várias novas tendências de consumo, baseado no que podemos nos referir, a princípio, como novos estilos de vida dos consumidores. Dentre eles, está o metrossexualismo. O termo metrossexual é relativamente novo, foi citado pela primeira vez na década de 1990, mais especificamente em 1994, pelo jornalista Mark Simpson em seu artigo "Here comes the mirror men", publicado no Jornal The Independent. No entanto, foi apenas em 2002, com seu artigo "Meet the metrossexual" que o termo deslanchou e passou a ser usado freqüentemente. Para Simpson, o metrossexual é o jovem homem, com alto salário para gastar, vivendo ou trabalhando na metrópole, porque é lá que estão as melhores lojas.

O marketing ainda não parece estar atento o bastante para este novo fenômeno. Uma das poucas menções que vemos é num recém-lançado livro de Mittal e colaboradores. Ali, os metrossexuais são definidos como "homens urbanos que têm um forte senso estético e que gastam muito tempo e dinheiro com sua aparência e estilo de vida" (MITTAL et al., 2008, p.441).

Assim, podemos deduzir que os metrossexuais sejam homens que acreditam que o cuidado com o corpo, a pele e o cabelo, dentre outras vaidades, não é apenas para mulheres. Segundo Garcia (2004), este "novo homem", se assim podemos dizer, gasta mais de $30 \%$ de seu salário com cosméticos e roupas, freqüenta salões de beleza e clínicas estéticas e passa boa parte de seu tempo em shoppings.

Por outro lado, a indústria já parece ter se apercebido deste fenômeno. A cada dia novos produtos são lançados para esse homem contemporâneo, estimulando o consumo masculino. Nos últimos dez anos, o crescimento do consumo de produtos de beleza para homens tem crescido anualmente a uma taxa média de $17 \%$ (GARCIA, 2004).

Mas será que podemos definir o metrossexual apenas pela sua volúpia e volume de consumo? Uma maneira de abordar este fenômeno talvez seja o enfocando como parte de algo mais amplo, de mudanças socioculturais correntes nas últimas décadas, para muitas assumidas como a pós-modernidade (JAMESON, 1994; LYOTARD, 1979).

Para discutir isto, precisamos nos ater primeiramente à própria noção de gênero. Ao assumir o gênero como uma construção sócio-histórica e cultural, vários estudiosos (e.g., Silva, 2000; WoODWARD, 2000) o têm compreendido como sendo, antes de uma condição em si, uma questão de identidade.

Neste sentido, a questão da identidade tem sido amplamente debatida, uma vez que mudanças estão acontecendo e velhas identidades estão sendo questionadas e dando espaço para novas possibilidades. Para alguns estudiosos (e.g., BAUMAN, 2005; HALL, 2005) a pósmodernidade tem cooperado fortemente para a possibilidade desses novos olhares. As identidades, que antes eram vistas como sólidas e fixas, hoje, com o "sujeito pós-moderno", começam a ser percebidas como fragmentadas, se transformando continuamente; como algo móvel, em constante diálogo com o social.

Isso se torna mais forte com a questão da mundialização - faceta cultural da globalização - que tem propiciado uma cultura híbrida, sem demarcação de fronteiras. Assim, as identidades começam a ser mescladas, influenciadas umas pelas outras (ORTIZ, 2003). Com 
isto, assistimos continuamente a um fenômeno de "produção de novas identidades" (HALL, 2005, p.84).

Ora, parece-nos que seja justamente um tipo deste fenômeno que vemos ao nos depararmos com os metrossexuais. Sendo assim, nossa premissa é de que o metrossexualismo se caracteriza como uma identidade cultural pós-moderna e, além disto, que seja fruto de uma possibilidade do consumo, ou seja, que se trate de uma identidade possível apenas por estar num dado tempo e num dado espaço: a sociedade [pós-moderna] de consumo.

Mas como se constitui esta identidade? Com esta questão em mente, o presente estudo teve por objetivo compreender a construção da identidade metrossexual. Uma das conclusões a que chegamos foi a de que esta identidade tem nos significados de consumo um de seus elementos constituintes.

\section{FUNDAMENTAÇÃO TEÓRICA}

Para dar conta da discussão teórica necessária ao embasamento do trabalho proposto, a presente seção divide-se em três partes. Na primeira, o fenômeno da centralidade da construção de identidades culturais fragmentadas sob a égide da chamada pós-modernidade. Em seguida, este aspecto é delimitado ao contexto imediato da pesquisa, na medida em que discutimos a questão da identidade de gênero na contemporaneidade, uma vez que a discussão identitária do metrossexualismo é inserida neste campo. Por fim, fechamos com a relação entre consumo e a constituição da identidade, perpassando os dois níveis anteriormente discutidos.

\subsection{A identidade cultural na pós-modernidade}

A identidade tem sido discutida nos dias atuais como uma produção histórica a partir de construções discursivas que institucionalizam e/ou legitimam lugares e poderes. Ao estudarmos identidade como construção às posições de sujeito, falamos de instituições que elaboram e convencionalizam um resultado bem-sucedido de articulação ou fixação do sujeito aos fluxos desses discursos. Foucault (1996) discute sobre isso quando argumenta que em toda sociedade a produção do discurso é ao mesmo tempo controlada, selecionada, organizada e redistribuída por certo número de procedimentos que têm por função conjurar seus poderes e perigos, dominar seu acontecimento aleatório, esquivar sua pesada e temível materialidade (FOUCAULT, 2006. p.8).

Um discurso que constitui identificações aos sujeitos e que institucionaliza, controla, organiza de que forma devemos pensar sobre ele. Por isso falamos que essa produção da identidade está intimamente ligada não só a esse controle que instituições fazem, mas como distribuem, pois quando falamos em identidade cultural falamos de comunidades e de que forma estas dão resposta a essa produção. Assim, essa produção não é aleatória, ela tem um projeto político e histórico.

Hall (2005) complementa o que Michel Foucault fala sobre essas práticas discursivas e como sua materialidade é pesada e temível. Desde o século XVI, com o Renascimento e com a promoção do indivíduo moderno, centrado, racional, até o século XVIII com o discurso científico, a filosofia e o sujeito iluminista do conhecimento, da prática, da individualidade 
que coloca em questão a ordem social, econômica e, principalmente, religiosa com o estudo da lógica, da matemática que passou a definir o indivíduo como uma entidade maior. Por isto o sujeito passou a ser visto como mais localizado e definido no interior dessas grandes estruturas e quem legitimou muito esse espaço. Foi a biologia darwiniana que dizia que a razão tinha uma base na Natureza e a mente um fundamento no desenvolvimento físico do cérebro humano. Assim como Darwin, a sociologia também materializou esse sujeito racional e caracterizou sua relação com a sociedade a partir de uma externalização do interior e internalização do exterior do sujeito, ou seja, ele é uma construção do social em que está inserido: externaliza ou coloca em prática o que foi internalizado pelo ambiente que vive. $\mathrm{E}$ aqui, encontramos a figura do indivíduo isolado, exilado ou alienado, colocado contra o pano de fundo da multidão ou da metrópole anônima e impessoal.

Se no iluminismo tínhamos um sujeito totalmente centrado, unificado, dotado das capacidades da razão, hoje isso parece cair por terra. Para Hall (2005) o sujeito como tendo uma identidade unificada e estável, está se tornando fragmentado; composto não de uma única, mas de várias identidades. Para o autor, o fim do século $\mathrm{XX}$ trouxe consigo todo um questionamento sobre essas práticas culturais de construção de identidade. E isso afeta paisagens culturais de gênero, classe, sexualidade, etnia, raça e nacionalidade. As identidades pessoais estão sendo abaladas pelas transformações por que passa o mundo contemporâneo, pela perda de um "sentido de si” estável - a identificação que fazemos de nós mesmos. Assim, temos um duplo deslocamento do sujeito: descentramento tanto do seu lugar social e cultural quanto de si mesmo.

Assim, para definir o que seja essa identidade cultural, Hall (2005) apresenta que somos construídos pela alteridade, pelo contato com o outro. Não temos uma identidade pronta, já estabelecida no nosso nascimento; estamos em constante busca da "identidade", ou seja, nos construímos dia-a-dia. Com isso, a identidade torna-se uma celebração móvel, formada e transformada continuamente; construída nas vivências e convivências, no contato com o outro.

Com isto, a idéia de uma identidade única, estabelecida e definida, passa a ser vista como não fazendo sentido. A compreensão da identidade passa a ser intimamente ligada ao "lugar" em que o sujeito está, ou seja, o indivíduo assume identidades diferentes dependendo de "onde" se encontre, dos papéis sociais que desempenha, seja no convívio familiar, profissional, com os amigos, entre outros. Como afirma Woodward (2000), somos posicionados - e também posicionamos a nós mesmos - de acordo com os "campos sociais" nos quais estamos atuando.

Um dos grandes acontecimentos que contribui para o deslocamento da identidade é a mundialização. Ela derruba fronteiras, acelera os fluxos e os laços entre as nações, tornando o mundo menor e diminuindo as distâncias. É através dela que o mundo se conecta em poucos segundos, fazendo com que a barreira entre tempo e espaço já não mais exista. É no conhecer de outras culturas e identidades que o sujeito toma conhecimento de novos mundos, e a aceitação do novo parece estar se tornando "comum", fazendo com que novas combinações parecem desordenar o ordenado (HALL, 2005)

Bauman (2004), por sua vez, afirma que a fragilidade da identidade não deve mais ser ocultada, uma vez que a identidade não é sólida como uma rocha, nem é algo para toda a 
vida, pois ela é negociável de acordo com os caminhos que o indivíduo escolhe e com a forma como esse age. Assim, segundo ele, o sujeito assume identidades diferentes em diferentes momentos e percebe-se de que forma essa construção de identidade é algo relacional. Para o autor, o indivíduo social tem perdido sua base solidificada na modernidade e passa por grandes transformações na pós-modernidade. Essas transformações ocorrem pelas novas possibilidades que o sujeito pós-moderno se depara diante de uma sociedade em contínuas mudanças e aceitações. Essa nova sociedade parece abrir espaço para o diferente, torna-se maleável para o que antes era conhecido como "o estranho", o "fora do padrão"; as identidades são assumidas de forma mais livre e o padrão começa a ser coisa do passado; vivemos uma época "líquido-moderna", em que o indivíduo livremente flutuante, desimpedido, é o herói popular; "estar fixo" - ser "identificado" de modo inflexível e sem alternativa - é algo cada vez mais malvisto.

Tendo isso em vista, Hall (2005) ressalta que as sociedades pós-modernas são caracterizadas pela "diferença"; são atravessadas por diferentes divisões e antagonismos sociais que produzem uma variedade de posições do sujeito. Woodward (2000) também aponta que a identidade é relacional, marcada pela diferença, ou seja, a identidade é estabelecida por uma marcação simbólica em detrimento a outras identidades. A identidade só existe porque há a diferença. E é por essa demarcação de diferença que a sociedade passa a ser dividida em grupos diferenciados. Assim, se pode pensar sobre a construção do sujeito enquanto ente cultural e inserido num espaço dinâmico e com ressonâncias históricas. Para a autora, a cultura demarca fronteira e põe em evidência as diferentes identidades, uma vez que cada cultura tem uma forma de enxergar o mundo, e é a partir dessa forma de enxergar que alguns são incluídos e outros excluídos em determinada sociedade.

Neste sentido, a identidade tem sido discutida como uma produção histórica a partir de construções discursivas que institucionalizam e/ou legitimam lugares e poderes. Ao estudarmos a identidade como construção de posições de sujeito, falamos de instituições que elaboram e convencionalizam um resultado bem-sucedido de articulação ou fixação do sujeito aos fluxos desses discursos; um discurso que constrói identificações ao sujeito e que institucionaliza, controla, organiza de que forma devemos pensar sobre ele. Por isso falamos que essa produção da identidade está intimamente ligada não só a esse controle que instituições fazem, mas como distribuem, pois quando falamos em identidade cultural falamos de sociedade e de que forma dão resposta a essa produção. Assim, essa produção não é aleatória, ela tem um projeto político e histórico. Se hoje debatemos sobre um sujeito descentrado, com identidades que são construções, é porque todo um debate sobre isso já foi levantado e abordado por teóricos que passaram a questionar sobre o sujeito pronto, acabado sem historicidade (HALL, 2005).

Assim, outro aspecto que deve ser observado em relação às identidades é que elas são atos lingüísticos de criação, ou seja, já que são produzidas. Não são inatas ao sujeito, mas são firmadas pela cultura e sociedade. É através dos atos lingüísticos que os signos são formados, eles só adquirem valor ou sentido numa cadeia infinita de outras marcas gráficas ou fonéticas que são diferentes deles. Esses atos lingüísticos permitem que os sujeitos de determinada comunidade comuniquem-se e compreendam-se, por utilizarem um mesmo sistema de regras e que está relacionada com a produção de discurso. Discurso, este, que passa a legitimar o 
que é ser homem, mulher, ou seja, que atitudes e/ou características devem ter na sociedade (SILVA, 2000).

Tendo em vista que a língua é um contrato coletivo no qual os membros de uma comunidade se submetem para poderem se comunicar, ela é de fundamental importância para entender esse processo de construção da identidade. Isso se dá porque é através dela que se legitimam lugares, ou seja, é por meio dos atos da fala que instituímos a identidade e a diferença como tais. Dessa forma observa-se que cada comunidade tem suas "regras" lingüísticas e é através delas que se diferenciam uma das outras. No entanto, vale ressaltar, que a linguagem é instável, uma vez que o signo é uma marca que está no lugar de outra coisa. Não há nada nele nada que remeta a algo existente; ele representa uma coisa em detrimento do que essa coisa não é. Dessa forma, o signo é marcado pela diferença e sua a existência adquire sentido tendo por base os outros signos e o contexto social, como a identidade e a diferença (SILVA, 2000).

\subsection{Identidade de gênero}

A questão do gênero é uma dessas construções ao colocar em cheque o que é ser masculino e feminino. Se antes se pensava a identidade de gênero como algo biológico, hoje é observada como construção social e cultural, a construímos dependendo de onde estamos e com quem.

Para debatermos sobre a identidade de gênero, nos parece necessário observarmos um pouco de história, e o que levou a essa discussão. De acordo com Cecchetto (2004), até pouco tempo atrás, as questões de gênero não eram contestadas, pois eram vistas como inscritas na natureza, ou seja, determinado pelas diferenças biológicas.

Pinho (2004, p.65), afirma, por sua vez, que o movimento feminista4 provocou um "abalo sísmico nas identidades e nas políticas de representação", e complementa que além desse movimento, os movimentos dos gays e lésbicas em busca da liberdade sexual e dos direitos humanos, fizeram emergir a categoria gênero. Segundo o autor, não apenas a mulher "foi desenhada na história pela pena do poder e da dominação masculina, mas o próprio homem descobriu-se surpreso quando percebeu que também era um artefato de gênero" (PINHO, 2004, p.65).

A sociedade molda o gênero, pois existem "regras" que definem o que é ser feminino e o que é ser masculino. Ideais convencionais e regras prescritas de comportamentos tornaram-se os principais guias pelos quais os indivíduos são julgados como pertencentes a este ou aquele sexo. E isso tem uma conotação histórica uma vez que convenções foram institucionalizadas a fim de que fosse delimitado o que se conceitua homem e mulher; regras, comportamentos, hábitos que aprisiona em um conceito. Na pós-modernidade, contudo, a identidade de gênero torna-se um produto cultural maleável, um instrumento de autoexpressão. Assim, desconstruído em seus significados concretos, o gênero é meramente um elemento possível para adicionar à mistura da identidade. Onde o que, na modernidade, era pré-estabelecido

\footnotetext{
${ }^{4}$ Nolasco (1993) discorda que o movimento feminista impulsionou a crise da identidade masculina, para ele isso se dá devido a crise no mundo do trabalho e na família, como afirma ele "restringir a transição vivida hoje pelos homens a particularidades e à história do movimento das mulheres é negar que o próprio movimento de mulheres também decorre das transformções sociais iniciadas no século XVII” (p. 23)
} 
como "coisa de homem", com a pós-modernidade, começa a se fragmentar, dando espaço pra novas possibilidades de construção da identidade de gênero. O que está em debate, hoje, é que na sociedade pós-moderna noções tradicionais de feminilidade e masculinidade se cruzam como sendo antiquadas e ilusórias. O que se observa são os caminhos para novas direções, para novas possibilidades e muitas certezas se tornam incertas e novas identidades de gênero são formadas (KACEN, 2000).

Segundo Louro (1999), as inscrições de gênero é feita sempre no contexto de uma determinada cultura e, portanto, com as marcas dessa cultura, compostas e definidas por relações sociais. A identidade masculina e a feminina não apresentam características inatas, tal identidade é determinada por um senso de distinção de uma sociedade sobre o que é essencial para um e/ou característico para outro e vice-e-versa. Assim percebemos que a identidade de gênero é condicionada pela sociedade, e não definida pelas genitálias. Uma vez que a identidade de gênero se dá no contexto sócio-cultural, observa-se que essa identidade é construída tendo por base o ambiente em que se vive, a família, amigos, escola.

Oliveira (2004) discute uma trajetória sobre a masculinidade, ressaltando alguns aspectos da feminilidade, e afirma que na sociedade burguesa as funções da mulher foram claramente definidas, a elas cabia a função de mãe, educadora, provedora do afeto e carinho; aos homens, ficaria destinada a esfera pública a esfera do poder, havendo dessa forma uma separação de característica e comportamentos típicos de cada gênero. Segundo o autor, para um ideal de masculinidade, "as qualidades como autocontrole, disciplina, força, iniciativa, coragem, responsabilidade etc., definiam as virtudes sociais" (OLIVEIRA, 2004, p. 79).

No passado, os homens eram vistos como fortes, dominadores, provedores do sustento familiar; as mulheres, por sua vez, como responsáveis pelo cuidado com a casa, com os filhos, pessoas dóceis e frágeis. Neste sistema social a masculinidade é glorificada e a feminilidade desvalorizada. Entretanto, com a pós-modernidade, observamos que estão ocorrendo hibridações dos gêneros. Homens já podem chorar, se dizer sensíveis. Mulheres já podem ser chefes de família e não apenas mães ou donas de casa; podem ser profissionais, ocupar lugares no mercado de trabalho.

$\mathrm{Na}$ condição pós-moderna, a identidade de gênero torna-se um produto cultural maleável, um instrumento de autoexpressão. Não é mais um simples fato natural, mas um pastiche de possibilidades. E é nesse "pastiche de possibilidades" que ocorre o reconhecimento do outro, homens assumem seu lado "feminino" e mulheres seu lado "masculino", não no sentido de ser tornar afeminado ou masculinizada, mas de assumirem características e comportamentos que antes eram aceitos como exclusivos de um ou de outro (KACEN, 2000).

Na opinião de Louro (1999), os sujeitos têm identidades transitórias e contingentes. Dessa forma, já não se tem mais uma única identidade, mas "papéis são interpretados dependendo do contexto", ou seja, uma mãe que é carinhosa e dócil com seu filho em casa pode ser "feroz" como chefe em uma empresa. Os homens, por sua vez, que sustentam sua imagem de "macho" no ambiente de trabalho ou no meio social, podem ser o pai mais sensível no lar. E as possibilidades não acabam.

\subsection{O consumo como condição de identidades [e] de gênero}


$\mathrm{Na}$ medida em que novas perspectivas vão ganhando espaço na sociedade contemporânea, o consumo toma passa a ser discutido com ênfase nunca antes vista. A visão utilitarista do consumo, em que o consumidor nos é apresentado como indivíduo centrado, que não sofre influências na sua decisão de compra, apenas satisfaz uma necessidade, é questionada. De acordo com Firat (1991), o projeto pós-moderno tem revertido a ênfase e a ordem das coisas. O projeto central não é mais a produção, mas sim o consumo. Ele conclui que o consumo se tornou um meio de autorrealização, autoidentificação, um meio de se produzir com a própria imagem. Não há mais a culpa de consumir em detrimento a produzir, e gastar já não é mais pecado.

Para Baudrillard (2003), a identidade moderna é mais bem compreendida por meio da idéia de consumo. Segundo ele, escolhemos uma identidade para nós mesmos na vitrine do mundo social pluralizado; deparamos reflexivamente com ações, experiências e objetos como parte da necessidade de construir e manter a própria identidade.

Nesta linha, Leão e Mello (2007) afirmam que o consumo - e não a produção - se torna o motor das sociedades e, assim, as pessoas passam a ser mais "importantes" para estas enquanto consumidores e não mais enquanto trabalhadores. Para os autores, o consumidor não pode mais ser visto como aquele que busca a relação satisfatória de custo versus benefício, mas sim as experiências adquiridas através do próprio consumo e do significado que este passa a desempenhar em suas relações. O consumo passa a ter significado, não apenas o consumir para suprir uma necessidade, mas consumir como ato de "significar" na sociedade.

Dessa forma, o consumo assume um papel fundamental na sociedade contemporânea, pois como afirma Slater (2002), ao consumirmos rotineiramente, construímos identidades e relações sociais a partir de recursos sociais. Ele afirma que os consumidores tomam decisões de quem são e querem ser e usam bens, serviços e experiências adquiridos para realizar esses projetos de identidades.

Assim, consumo e cultura se mesclam. Para Baudrillard (2003), é através de formas de consumo culturalmente específicas que produzimos e reproduzimos culturas, relações sociais e, na verdade, a sociedade. A cultura dos indivíduos indica o "valor" que determinado produto pode ter naquele contexto social. Assim, a cultura de uma sociedade interfere na forma de consumo. Diferentemente do que se observa na visão econômica, na qual o foco era a individualidade, na sociedade contemporânea o que faz o indivíduo fazer parte deste ou daquele grupo, desta ou daquela camada social é o consumo. Já não é mais a religião ou política que dão as diretrizes para o indivíduo, mas sim o próprio ato de consumir. Os significados e rituais de consumo demarcam, portanto, as categorias e classificações que constituem a ordem social.

A identidade que antes era construída tendo por base a família, amigos, escolas, é concebida hoje por outras possibilidades discutidas por vários autores na contemporaneidade, como é o caso de Slater (2002), que afirma é em parte através do uso de bens e serviços que nos formulamos enquanto identidades sociais.

Assim, o consumo assume papel central na construção da identidade, uma vez que ele carrega significados simbólicos, e estes significados definem a que grupo determinada pessoa pertence. O que uma pessoa consome diz muito a respeito de sua identidade e a faz interagir 
com a sociedade, uma vez que a aloca em determinados grupos. Neste sentido, há uma relação entre a identidade da pessoa e o que ela usa, assim, a identidade é tanto social quanto simbólica (WOODWARD, 2000).

Firat (1998) sugere que a ética do consumo e faz a construção da identidade um passatempo de consumo. Se na modernidade tínhamos o conceito de homem produtor e da mulher consumidora, na era pós-moderna, a ascendência da cultura de consumo tem destruído as diferenças "masculino-feminino", tornando todos consumidores.

O que se observava, na "modernidade", era a exigência do padrão da beleza feminina. Na pós-modernidade, essa exigência permanece e cada vez mais forte, mas começa a ser uma exigência também para o homem, o que descaracteriza a estabilidade sólida do gênero masculino. Essas novas exigências para com o homem estimulam o consumo, uma vez que se espera que eles estejam cada vez mais bem cuidados, bonitos e atraentes (KACEN, 2000).

De acordo com Campbell (2006), algum tempo atrás a identidade estava relacionada muito mais ao status e à posição que ocupava em várias instituições e associações, como família, trabalho, religião, raça, etnia e nacionalidade do que com algo tão "insignificante" quanto o gosto pessoal, o que ele diz ocorrer hoje em dia. $\mathrm{O}$ autor ressalta que o significado de consumir está frequentemente relacionado à afirmação, à confirmação, ou até mesmo à construção da identidade e afirma que as pessoas ao consumirem recriam-se, adotam ou até trocam de identidade de uma forma muito simples, como se troca de roupa.

Neste sentido, a mídia influencia fortemente esta descaracterização e estimula as novas formas de consumo. Na propaganda o homem sempre foi trabalhado como sendo marido ou homem de negócios, e a mulher como dona de casa, mãe, e preocupada com a beleza. Nos dias atuais, contudo, os papéis se misturam: homens são mostrados como pais; mulheres como "mulheres", e não apenas mães, e também como profissionais. As noções de "papel da mulher" e "papel do homem" muitas vezes se invertem.

\section{PROCEDIMENTOS METODOLÓGICOS}

Para a realização da presente pesquisa adotamos a abordagem qualitativa. A coleta de dados foi realizada por meio de um tipo específico de entrevista em profundidade: a entrevista longa (MCCRACKEN, 1988).

McCracken (1988) propõe como base da "entrevista longa" a utilização do investigador como instrumento. Seu objetivo é propiciar uma apreciação mais detalhada e sistemática da experiência do pesquisador com o tema em questão. $\mathrm{O}$ pesquisador deve relacionar e examinar as associações, incidentes e pressupostos que cercam o tópico da pesquisa em sua mente. Com isto, o pesquisador poderá extrair de sua própria experiência as propriedades sistemáticas do tópico de pesquisa, separando o estrutural do episódico e o cultural do idiossincrático. Este processo deve tornar o pesquisador mais sensível a como os entrevistados concebem o assunto relativo à pesquisa.

McCracken (1988) apresenta a realização de sua "entrevista longa" em duas partes. A primeira, relativa à construção do roteiro e a segunda ao procedimento da entrevista em si. Para a construção do roteiro, o autor sugere que se comece por questões biográficas, que permitem que o pesquisador verifique os detalhes descritivos da vida do entrevistado. Em seguida, deve se definir questões numa série de áreas de interesse da pesquisa, pré-definidas. 
As primeiras são perguntas não intrusivas, que se tornam fácil de fazer, já que estas devem suscitar testemunhos ainda abertos, para, só a partir daí, dar início a questões específicas das categorias de interesse. Nesta nova etapa, o pesquisador precisará ser mais proativo, o que o guiará para uma postura mais intrusiva. Os primeiros minutos das entrevistas são fundamentais para seu prosseguimento e êxito. Neste sentido, o pesquisador deve parecer simples e concordante, ao invés de apresentar uma atitude crítica, e fazer perguntas informais, como se de um bate-papo, para criar a atmosfera propícia. Uma vez que as preliminares estejam completas, o pesquisador deve dar início às perguntas planejadas.

Segundo McCracken (1988), esse tipo de entrevista nos possibilita o acesso ao mundo mental do indivíduo, para vislumbrar as categorias e a lógica na qual este vê o mundo, além de levar o pesquisador para dentro de sua vida, para que se veja o conteúdo e o padrão de sua experiência diária; um método que oportuniza que se entre na mente de outra pessoa para que se experiencie o mundo como esta o faz, sem, com isto, transgredir sua privacidade.

O corpus da pesquisa foi construído por meio de entrevistas concedidas por homens das cidades de Recife, em Pernambuco, e de João Pessoa e Campina Grande, na Paraíba. Um roteiro não estruturado foi elaborado, de forma a permitir a livre expressão dos entrevistados, bem como que novas perguntas fossem realizadas no decorrer do processo, de acordo com as respostas obtidas. Assim, conduzimos a entrevista como sendo um bate-papo, sem críticas e nem posicionamentos por parte do entrevistador. No entanto, tivemos a preocupação de abarcar todos os tópicos do roteiro, a fim de não perdemos informações que poderiam vir a serem importantes para a compreensão da identidade metrossexual. Para se certificar que o perfil do entrevistado atendesse ao objetivo do trabalho, questões-filtro, com base na definição anteriormente apresentada de Mittal (2008) para metrossexuais, foram incluídas no início das entrevistas.

Inicialmente não tínhamos um número definido de quantas entrevistas seriam realizadas, pois, como afirmam Bauer e Aarts (2002), pouco se pode dizer sobre o tamanho ideal de um corpus de pesquisa. Segundo Godoi e Matos (2006), na pesquisa qualitativa o investigador está impedido de determinar previamente o número de entrevistas necessárias à sua investigação. Um ponto-chave que se deve ter em mente é que, quando os relatos comecem a se tornarem semelhantes, mais entrevistas não melhoram necessariamente a qualidade ou levam a uma compreensão mais detalhada do fenômeno (GASKELL, 2002).

Assim, utilizamos o critério de saturação para sabermos quando deveríamos encerrar as entrevistas. De acordo com Bauer e Aarts (2002, p.59), "saturação é o critério de finalização: investigam-se diferentes representações, apenas até que a inclusão de novos estratos não acrescente mais nada de novo". A saturação nesta pesquisa ocorreu na oitava entrevista. No entanto, realizamos ainda mais três entrevistas para nos certificarmos de que nenhum dado novo iria surgir, totalizando assim onze entrevistas realizadas, além de outras duas iniciadas, mas não concluídas pelo fato dos entrevistados não terem sido identificado como metrossexuais após as questões-filtro. As entrevistas longas foram feitas com o uso de gravador, autorizado pelos entrevistados. Cada entrevista teve duração de 40 a 60 minutos, o que originou 135 páginas transcritas.

O critério adotado para selecionar os entrevistados foi o de indicação (estratégia bola-deneve). Este critério nos pareceu o mais apropriado por não ser fácil identificar o sujeito 
metrossexual, pois muitos deles ou não têm consciência de que são ou mesmo a que se refere esta nomenclatura ou podem não querer assumir esta identidade por possíveis conotações preconceituosas.

Para a análise de dados utilizamos a análise do discurso. Surgida como uma forma não positivista de se desenvolver o conhecimento e tendo como pano de fundo a virada lingüística, que colocou o problema da linguagem no centro das discussões filosóficas no século $\mathrm{XX}$, a análise de discurso, parte do princípio de que um enunciado nem sempre quer dizer a mesma coisa, mas é dependente do contexto em que é dito, em que as condições do exercício da função enunciativa são sempre determinadas no tempo e no espaço (FOUCAULT, 2002). Isto quer dizer que a compreensão da sintaxe e da semântica das orações não garante sua compreensão e que nenhum pronunciamento é neutro ou isento de valor. Tomemos como exemplo a seguinte frase: "Meu carro quebrou". Se dito a um amigo na saída do trabalho, isso pode significar um pedido implícito de carona. Se dito à pessoa que lhe vendeu o carro, pode ser uma acusação. Ainda, se dito a um professor após um atraso para a aula, pode ser uma desculpa ou explicação. Para Pêcheux (2002), a análise de discurso tem intrinsecamente três características para o analista: a primeira é a de que descrever se torna indiscernível de interpretar; a segunda, de que todo enunciado é, de alguma maneira, mais do que um simples texto; finalmente, a terceira, de que todo discurso constitui ao mesmo tempo um efeito das filiações sócio-históricas de identificação e um trabalho de deslocamento no seu espaço. Nesta perspectiva, Brandão (1997) propõe que a análise de discurso tem como diferença principal o desafio de realizar leituras criticas e reflexivas que não reduzam o discurso a análises de aspectos puramente lingüísticos nem o dissolvam num trabalho histórico sobre a ideologia.

Em nosso processo analítico, o primeiro passo foi a transcrição das entrevistas. Para Gill (2002, p.251), "uma boa transcrição deve ser um registro tão detalhado quanto possível do discurso a ser analisado. A transcrição não pode sintetizar a fala nem ser 'limpada', ou corrigida; ela deve registrar a fala literalmente, com todas as características possíveis da fala". Assim, todas as entrevistas foram transcritas por um profissional, como sugerido no texto de McCraken (1998). À medida que essas transcrições chegavam até nós, era feita uma revisão, ou seja, escutávamos novamente a gravação lendo a transcrição para ver se esta era fiel ao falado.

Para cada entrevista, fizemos entre três e quatro leituras, com o intuito de nos familiarizarmos com o texto. Essas leituras foram feitas em dias e horários diferentes. Este processo foi fundamental para partimos para a parte que nos pareceu a mais complexa da análise do discurso, que é a codificação de cada entrevista, através da qual ocorreu a análise de fato: a codificação das categorias através das quais emergiram os elementos de regularidades que respondem à pergunta de pesquisa.

Para a codificação, Gill (2002, p.254) sugere que "ela deve ser feita da maneira mais abrangente possível, de tal modo que todas as instâncias limítrofes possam ser incluídas, em vez de serem deixadas de fora”. Isso é importante para que não ocorra perda de elementos. Assim, chegamos a encontrar cerca de sessenta elementos, que foram trabalhados e refinados para originar as categorias. 
Procuramos, em seguida, a partir dos elementos encontrados, a convergência e variabilidade dos elementos, a fim de formarmos as categorias, ou seja, procuramos as semelhanças e diferenças nos dados para categorizá-los. Essa busca de padrões ocorreu em cada discurso/entrevista e depois foi buscada em todas as entrevistas, para que chegássemos a um padrão que abarcassem todas as entrevistas e elementos. À medida que íamos encontrando elementos novos a cada entrevista, recorríamos as anteriores para nos certificarmos que eles realmente não estariam presentes ali, ou se estavam e não tinham sido identificados de imediato. Nesse ponto da análise percebemos a importância de termos feito mais de duas leituras de cada entrevista, pois, à medida que elementos iam surgindo, lembrávamos ter visto alguma coisa referente a eles em entrevistas anteriores, o que nos fazia também voltar a elas.

Agrupamos os elementos encontrados em categorias e subcategorias. Estas, por sua vez, foram constituintes de grandes dimensões que tornaram possível chegarmos à resposta para a pergunta de pesquisa. Assim, verifica-se que para a análise do discurso realizada na nossa pesquisa, partirmos do geral para o particular, ou seja, dos elementos contidos em cada entrevista, para depois chegarmos às grandes dimensões que abarcam todas as onze entrevistas analisadas, como será discutido na análise dos dados propriamente dita.

\section{ANÁLISE DOS RESULTADOS}

No nosso estudo identificamos os metrossexuais se relacionam com os "objetos" do mundo material do consumo. Para Solomon (2002, p. 181), no caso do consumo "a palavra objeto é usado num sentido genérico e se refere a um produto (ou marca), um anúncio ou situação de compra". Nossa análise nos levou à identificação de quatro categorias, subdivididas em elementos relativos ao consumo, os quais passamos a descrever.

\section{Dispêndio}

Diz respeito ao que o metrossexual dá em troca do que quer alcançar. Para cuidar de si o metrossexual investe tempo e dinheiro, que são os dois elementos presentes nesta categoria.

\section{Tempo}

O metrossexual sente-se bem em cuidar de si e se envolve com esses cuidados. Para isto, ele dedica grande parte do seu tempo a essa atividade, como observamos a seguir:

O dia a dia de um homem vaidoso é... diferente de um homem que não é vaidoso justamente por isso, porque ele tem maiores preocupações, ele vai gastar mais tempo cuidando, é... passando hidratante... arrumando o cabelo... vendo se... se tá tudo bem, se a roupa... num é simplesmente acordou, tomou banho, jogou a roupa no corpo e foi... sabe, eu acho, o homem vaidoso tem que devotar mais tempo pra si próprio, pra cuidar de si, pra... cuidar do seu corpo, cuidar da aparência. (E4- L.283-289)

A partir do discurso acima, percebemos que o metrossexual investe mais tempo em si do que os outros homens, ele gosta da relação dele com os cuidados que tem e isso demanda tempo, pois ele faz por querer fazer e achar importante. 
Essa preocupação em relação aos cuidados com a boa aparência aumenta quando se vai para uma festa, ou seja, o tempo gasto parece ainda maior, por exemplo:

Sair pra uma festa tem que... ver os mínimos detalhes, tem que... tirar a barba, que quando eu vou trabalhar eu só tiro a barba no outro dia, aí se eu for sair durante a noite eu tiro, se eu tirei de manhã eu tiro de novo... à noite, aí vou faço aquelas, vou... tiro a barba ai passo hidratante, depois... vou vestir a roupa, vê se combinou, tudo. (...) É, leva, uma hora, uma hora e meia. (...) Sempre, levo mais horas assim, tratando da... do rosto, minha barba é muito complicada de tirar..., aí depois, o cabelo, meu cabelo num é muito complicado não, passo um gelzinho já fica... fica bom. (E11- L. 217-228)

O metrossexual se apega aos detalhes do seu visual, como retratado acima, e para ir a uma festa, ou a algum lugar, ele quer estar com uma imagem impecável, dessa forma dedica a isso grande parte de tempo.

O tempo que o metrossexual concede à sua "produção", ou seja, a escolha de roupa, sapato, entre outros, é algo que merece ser destacado. Ao contrário da ideia de que o homem pega a primeira roupa que vê, este homem dedica tempo a isso e se envolve com essa escolha:

(...) então eu olho a cueca, olho a meia, olho a calça, o sapato, a camisa, eu perco acho que nisso eu perco uns vinte a trinta minutos sentado na frente do meu guarda-roupa, olhando o que vou usar, quando eu tenho tempo pra isso de véspera já...separo um dia antes, mas normalmente eu não tenho, quando chego em casa vou entrar na internet, aí eu não faço isso, de manhã eu acordo, ai é que eu vou olhar isso, a roupa que eu vou usar pra trabalhar, o óculos, o acessório que eu vou usar pra combinar também (...). (E9 - L.253-259)

Enquanto para vários homens a questão da preocupação com a aparência e com o tempo que é disponibilizado com os cuidados que se tem é considerado um fator dispensável, o metrossexual vê como um investimento. Ele vê além, e vê que aquilo o faz bem, o deixa bem em relação a ele mesmo, como dito abaixo:

Conheço muitos amigos que são vaidosos e que perdem muito tempo, não perdem, mas ganham muito tempo em sua... em manter uma aparência boa, em estar na academia, porque eles revertem isso na sua qualidade de vida, no seu humor com a família, com o trabalho e com a sociedade num geral. Então não é um gasto de tempo. você tá cuidando aqui de você, passando um certo tempo e uma certa (gagueja) uma certa quantia em dinheiro gastando com você, pra que você pegue isso e transforme em qualidade de vida. Transforme em felicidade, transforme em... ser uma pessoa melhor. (E5- L.198-295)

A partir do trecho acima, compreendemos que a relação que o metrossexual tem com os cuidados que dedica a si é algo imprescindível. Apesar de demandar tempo, ele acredita que esse tempo é um investimento e não vê isso como algo cansativo ou chato, pelo contrário, ele se envolve e percebe que terá bons frutos colhidos no futuro.

\section{Dinheiro}


MICHELE ARAUJO DA COSTA OLIVEIRA

ANDRÉ LUIZ MARANHÃO DE SOUZA LEÃO

Por estar envolvido com tudo o que pode melhorar sua aparência e com o que alimenta sua vaidade, o metrossexual investe, além de tempo, dinheiro, como segue:

É... eu acho que esse vaidoso ele acaba por... acho não, tenho certeza, vejo por mim mesmo, e eu tô tentando me controlar porque os gastos com isso se tornam muito altos e às vezes você deixa de comprar algo que necessita mais...por conta desses gastos. Então, às vezes eles chegam a somar das compras 20,30\%... e isso quando vai pro orçamento é alto. Então, por exemplo, eu não sei ficar sem (gagueja) os perfumes que eu uso, então tem os perfumes pra ocasiões mais especiais, os perfumes do dia a dia, os desodorantes ' $x$ ', então, os cremes do dia a dia, eu não deixo acabar um creme, então chega antes que acaba, pra não passar um dia sem...então...os gastos com o cabelo...então, é essa questão do gastar mais, talvez com o que o outro acharia de supérfluo. (...) Porque é algo que você passaria sem... a questão é: mesmo passando sem, como você passaria?... (...) Fundamental pra eles, porque essa questão do (gagueja) do que é supérfluo ou não é tudo uma questão de como você olha pra o objeto. Se esse objeto de consumo é o que eu preciso, é a minha necessidade, o que me satisfaz, então ele pra mim ele não é supérfluo... ele passa a ser uma necessidade básica... como comprar um feijão... (risos), comprar um arroz (risos), carne... então, ele é necessário também... então, a higiene pessoal não seria apenas a pasta de dentes e o sabonete... ou o barbeador, mas seria também todo um conjunto que vai além disso e, por isso, às vezes soma, nas compras, muito mais gastos do quê, é... (gagueja) uma cesta básica, por exemplo... né? Na minha, nas minhas compras somam bem mais. Então, teve um mês que, digamos, eu gastei... entre perfumes e..., que eu exagerei, foi um mês que eu exagerei, quando eu comprei tudo pra passar pelo menos dois meses, foi mais de quinhentos reais. (...) É... perfumes, loções pós-barba, loções durante a barba, principalmente esses cremes de barbear, que tem uma linha específica... que é muito boa... então, você não sente nenhuma dor durante o ato da (gagueja)... que é terrível, é chato fazer a barba. Mas depois também caiu a ficha... foi um gasto alto, mas foi pra dois meses. Você dividindo era só duzentos e cinqüenta e duzentos e cinquenta... dividido. (E1- L.269299).

Mesmo ele sabendo que gasta dinheiro e reconhecendo que exagerou, ele justifica para si que esse gasto é essencial. Isso fica evidente no discurso acima ao dizer que para ele é uma necessidade básica "ele passa a ser uma necessidade básica... como comprar um feijão... (risos), comprar um arroz (risos)". E também se justifica dizendo que o que comprou foi para dois meses. Mesmo sendo um gasto considerável, ele não se incomoda, para ele o dinheiro que investe com esses cuidados traz recompensas, por ele se sentir bem e feliz com sua aparência.

Além dos produtos de beleza, o metrossexual investe em roupas e em marcas, como abaixo:

Eu acho... eu acho, eu tiro por mim... né? eu... gasto bastante, descobri uma loja aqui pertinho do meu trabalho, eu não tenho muito tempo, eu trabalho de terça a sábado, domingo eu tô na minha casa descansando com os meus familiares, na segunda-feira, é médico, é banco, porque é o dia da minha folga... então não tenho muito tempo nem saco pra tá em shopping, aí descobri uma loja aqui pertinho, uma loja que vende grife aqui pertinho... aí foi a minha perdição né, as meninas... eu me tornei amigo das vendedoras elas ligam pra mim, ô Max vem aqui que tem... tá em promoção, Max tem... coleção nova, e eu vou... então eu gasto bastante tempo escolhendo, e dinheiro... porque não são peças baratinhas, um jeans lá, a média de lá é de trezentos reais, trezentos, tem peça de quinhentos reais, então é caro, você... você que se liga nisso realmente em grife, em marca... é caro. (E9- L. 87-97) 
Esse gasto de dinheiro realmente ocorre, como constatamos a partir do discurso acima, o metrossexual gosta de comprar e se envolve com as compras, ele demora escolhendo e investe dinheiro nisso.

Em algumas situações ele apresenta impulso de comprar, ou seja, compra mesmo que às vezes nem use tudo o que adquire:

(...) compro muitas coisas que eu não uso, se abrir o meu armário, a infinidade de perfumes que eu tenho... (E9- L.136-137)

No entanto, mas do que o gasto, o que importa é estar bem, se cuidar, mesmo que seja com produtos mais baratos. Segundo o discurso abaixo, não importa na realidade a quantia, mas que esses cuidados ocorram:

(...) tem todo tipo de produto então vai realmente de acordo com o poder aquisitivo, se você pode comprar um produto mais caro uma coisa mais importada, você compra, se não existe cremes populares, como eu tava dizendo, um Nívea, um Monange coisa de dez reais você compra um creme que vai durar no mínimo um mês, então... eu acho que... a aparência, a higiene, a... a vaidade vai de acordo com o seu poder aquisitivo também, mas existe produto pra todos os níveis... (E6- L.126-131)

O trecho acima caracteriza que mesmo sem ter tanto dinheiro, o homem deve investir em si, esse investimento não necessariamente precisa ser apenas com produtos caros, mas deve existir, para que pessoa tenha uma boa aparência.

\subsection{Tipos de Produtos}

Diz respeito a todos os produtos e serviços que o metrossexual valoriza e acha imprescindível. São três os elementos pertencentes a essa subcategoria: indumentária, produtos de beleza e serviços especializados.

\section{Indumentária}

Essa subcategoria está relacionada à questão da roupa, sapato e acessórios, produtos estes que apresentam uma grande importância para o metrossexual, uma vez que ele quer estar bem vestido e se preocupa em estar combinando camisa com calça, com sapato, como observamos em seguida:

É mais... ao me arrumar pra sair mesmo... eu tenho mais preocupação... às vezes eu já cheguei a trocar de roupa três vezes... num gostei da camisa que tava, num gostei da calça aí volto troco o sapato aí... se vai trocar a calça tem que trocar tudo... eu... eu sou muito preocupado com isso assim, eu só saio de casa quando eu realmente tô me sentindo muito bem, a roupa... tá muito boa... eu tô... até sem fazer academia há algum tempo... e tô me sentindo um pouco perdido dentro da roupa... até isso tá me incomodando... já... porque já não é toda roupa que eu posso vestir... tem umas roupas, umas camisas que exigem que eu esteja com o corpo um pouco mais forte, então tem várias camisas minhas que eu não visto há vários meses, porque eu não tô me sentindo bem pra vesti-las eu acho que eu ficaria muito... perdido dentro da roupa como eu costumo dizer... magro demais é uma roupa... que exige uma pessoa com um corpo mais... forte , com mais massa muscular. (...) Pra mim sim, eu tenho que tá... impecável, 
na hora de sair... se vou dar aula... a calça... tem que tá agradável, o sapato, a camisa eu não uso uma camisa mais de...uma vez... porque já amassou, já suou um pouco eu não gosto de usar depois... é... tenho que tá sempre combinando, camisa, calça, sapato... tem até uma calça minha que ela é mais escura e eu não gosto de usar com meu sapato preto porque eu acho que fica muito escuro... aí eu já uso com o bege... sabe essa... a questão de tá combinando... num é... algo compulsivo ah não tem que tá todo combinando, todo engomadinho. (E4- L.99-129)

O metrossexual se envolve com o tipo de indumentária que usa, como visto no trecho acima, ele observa o que está usando e se preocupa em estar bem aparentemente, as peças tem que apresentar uma relação harmoniosa entre si.

O tipo de indumentária usada por determinada pessoa diz muito dela e o metrossexual, ao saber disso, se envolve muito com essa questão, conforme abaixo:

A primeira coisa que eu olho na pessoa é a aparência... física né, como a pessoa está em forma, a forma da pessoa se está bem, a segunda é a vestimenta né assim, a roupa que você está usando é quem diz.... pelo menos diz pra mim, diz quem você é, diz a tua tribo, que indica pelo tipo de roupa que você tá usando, se a roupa é de marca, não tá com uma roupa de marca, mas se tá bem vestido, acho que é essencial. (E9- L. 35-40)

Para ele, o fato da indumentária falar por si, ou seja, a partir do que a pessoa usa, mostra quem ela é, como relatado acima. Isto é algo que faz com que ele se envolva em suas escolhas.

Outro aspecto destacado em relação ao mérito da indumentária é que através dela a pessoa pode sentir-se bem consigo mesmo ou mal, como citado abaixo:

É muito importante, a questão de roupa, porque a roupa..., às vezes, ela... tanto bota você pra cima, como ela pode te botar pra baixo, então...ele se preocupa muito com a roupa que ele veste. Se essa roupa tá boa, se essa roupa tá...vamos dizer assim... rejuvenescendo, tá envelhecendo... se essa roupa é adequada ao ambiente que ele vai. Tá entendendo? (...) Então ele se preocupa muito com a roupa que ele usa, inclusive, ele mesmo vai comprar a roupa dele sozinho..., às vezes num leva nem a mulher, ou a esposa, ou a namorada, pra que ela não influencie nesse gosto dele, então, ele mesmo vai só, ele... veste a roupa, ele olha a roupa, às vezes, ele... é... ele leva aquela roupa até mais pelo (gagueja) pelo o que ele viu como ele ficaria naquela roupa, por ele ter se sentido muito bem..., apesar da roupa nem ter dado nele kkk. É... como eu havia falado, a questão da roupa é muito importante, e o homem vaidoso se preocupa demais com isso. Ele chega ao ponto de comprar uma roupa que... se sentiu bem...mesmo se essa roupa (risos) mesmo que essa roupa não dê certo nesse momento, ele leva essa roupa porque ele achou que essa roupa vai ficar boa nele, vai rejuvenescer, então ele leva essa roupa, mesmo se essa roupa, naquele momento, não servir pra ele.... E você tem que saber usá-las nos ambientes adequados, nas situações adequadas... Tanto isso é verdade que existe 'personal estili', né, como você falou. (...) Style, personal style. (E5- L.263-286)

Existe uma forte relação entre o metrossexual e indumentária que ele usa. A partir do trecho acima visualizamos isso já nas primeiras linhas. A roupa que o metrossexual usa, por exemplo, apresenta uma relação direta com ele, é como uma relação de amor, como ressaltado no meio do trecho acima. Quando o metrossexual gosta de uma roupa, ele a compra e acredita que ela tem o poder de envelhecê-lo ou deixá-lo mais jovem. Assim, ocorre todo um envolvimento na escolha. 
A moda também faz parte do dia-a-dia do metrossexual, ele gosta de estar na moda e procura acompanhar essa moda, saber quais as tendências:

Tento me manter sempre que possível na moda, assistir alguns programas de... artista de... deixa eu ver... (...) da mídia... sempre que passa alguma reportagem eu presto atenção... (E10L.47-50)

Mas a moda para ele deve estar lincada ao que combina com ele, deve favorecê-lo, ele não vai usar a moda se ela não favorece seu corpo, como dito a seguir:

Você tem que... ter a consciência do que você quer pra você também você não vai viver no modismo, que tem moda que não, não, não... cabe para o seu tipo físico, eu por exemplo não podia nunca usar uma camisa baby-look né, ou existem mulheres que usam mini-saia que não tem nada a ver. Quer dizer, eu acho que você tem que se adequar ao seu tipo físico entendeu, eu acho que a moda é bom, é, mas como um referencial e não como uma obrigação a gente num vai ta obrigado a nada, é como eu tava dizendo, é o conjunto de...dessas coisas que fazem você com a aparência saudável. (E6 - L.162-168)

Assim, a moda é algo que envolve também o metrossexual, ele procura segui-la, mas escolhe peças que lhe favoreçam, como citada nos trechos acima.

Os acessórios, por sua vez, complementam a aparência do metrossexual, assim com as mulheres, este homem gosta de usá-los e até variá-los:

Acessórios, óculos que eu adoro comprar óculos, adoro pulseiras, adoro colares, sempre eu tô com alguma coisa, hoje eu tô sem porque, eu não me acordei pra tá me arrumando muito, botei um jeans e uma camiseta e vim trabalhar, mas normalmente eu tô de colar... tô com um anel diferente, eu gosto muito. (E9- L.150-153)

No discurso acima, percebemos que ele se envolve com esses acessórios, pois para o metrossexual, eles compõem a sua "produção".

\section{Produtos de beleza}

Antigamente não se ouvia falar em homem usando produtos para hidratar a pele, cremes anti-rugas, óleos trifásicos. No entanto, há uma grande demanda desses produtos por parte desse novo homem, ele incorpora isso da mesma forma que usa um sabonete, um creme de barbear ou um desodorante, como elucidado no seguinte trecho:

(...) passo um creme no rosto, passo um creme mais barato, porque o do rosto é mais caro, no pescoço, passo um creme nos cotovelo porque o dia a dia resseca, passo um óleo trifásico no corpo todinho e passo um creme no pé... (E6- L.307-309)

Mais o uso desses produtos por parte do homem está cada vez mais se ampliando, e, alguns metrossexuais, recorrem a maquiagem para disfarçar ou ressaltar alguma coisa, como destacado nos trechos abaixo:

(...) tem um colega, por exemplo, que além disso tudo, ele ainda usa uma certa maquiagem, então tem um corretivo, ele recorre a isso sem nenhum problema...até um brilho labial pra dar um realce. (E 1- L. 63-65). 
(...) e também eu uso, eu uso... uma base né, eu uso corretivo no rosto, as vezes eu uso base também pouquinho (...) pancake, pancake eu uso também quando eu vou sair né, fica com a aparência mais bonita. (E2- L.358-362)

A partir desses dois trechos, observamos que o metrossexual é diferente dos outros homens, ele busca recursos que o deixem melhor, mesmo que para isso se torne adepto de produtos antes vistos como femininos, como o caso da maquiagem citada acima.

\section{Serviços especializados}

Diz respeito à gama de serviços disponíveis no mercado para atender esse novo público, metrossexual, que está aflorando fortemente nos dias atuais. Se antes o máximo que os homens faziam eram ir a um barbeiro, cortar o cabelo e fazer uma barba, hoje eles procuram salões, dermatologistas, clínicas de estéticas, como ressaltado no trecho abaixo:

Hoje existe um mercado especializado em cremes masculino (sic), os salões hoje já tem especialista para atendimento ao homem entendeu, existe salas especiais para esse atendimento, que o homem ainda fica meio envergonhado de ficar no salão diante de tanta mulher né, hoje o homem já faz umas luzes no cabelo...né, já faz um botoxzinho, quer dizer, eu acho que daqui a um período já vai ter salões exclusivamente para homem, com atendimentos que não é aquele da barbearia antiga né, que homem só fazia a barba, o cabelo, o básico, no máximo uma unha, quer dizer, aqui em Recife não, mas em São Paulo e no Rio já existem salões, clínicas exclusivamente, como a mulher tem aquele...banho de lua, o dia da noiva, o dia daquilo, hoje já tá se fazendo também para o homem né, aquele homem vaidoso que quer ter um dia especial né, um relaxamento, uma massagem, entendeu tudo isso que é voltado para a vaidade e pra saúde. (E6- L.278-288).

O metrossexual começa a se envolver com o que o mercado disponibiliza para ele. Os serviços especializados como destacado em todo o trecho acima, se voltam para esse novo homem, fazendo com que ele se volte para as novidades e se torne adepto delas.

A cada dia surgem novos serviços destinados a esse público e a tendência é isso se expandir, como dito no discurso a seguir:

(...) hoje São Paulo, se você for observar, já tem clinica de estética voltada só pra homem, e assim, eu acho que é esse o grande desafio do mercado hoje em dia é quebrar esse tabu que seja na verdade voltado para o homossexual, em nenhum momento na clinica tinha alguma coisa voltada para isso, ou que tinha essa preocupação ou o que se tinha poderia até ter, mas assim, é o tratamento é um tratamento diferenciado, porque sabe que é, já vem na exigência do mercado, a textura da pele do homem é diferente, como o homem se comporta o que vai ter na verdade num ambiente desse, com certeza vai ser revista de carro... já vai ter uísque, vai ter champangne, vai ter uma vodka, já vai ter uma coisa diferente e mais voltada para o publico masculino. (E8- L.255-268)

O metrossexual gosta dos serviços que começam a ser destinados a ele, e se envolve com isso, como demonstrado no inicio do trecho acima. Acredita que os tabus estão sendo quebrados e que os homens passam a procurar o que vem sendo direcionado a eles.

\subsection{Manter-se informado}


O metrossexual sabe que a indústria cada vez mais está dedicando espaço para suas necessidades e desejos, ou seja, se a indústria antes era voltada para o público feminino, porque esse era o publico considerado ideal, que mais consumia, hoje a cada dia ela se expande para os homens e apresenta novidades constantemente. Essa subcategoria é composta por dois elementos que melhor a explica. São eles: novos produtos/tecnologias e técnicas de cuidados.

\section{Novos produtos/ tecnologias}

Com a expansão da indústria, novos produtos e tecnologias vão surgindo rapidamente e o metrossexual gosta de ter conhecimento sobre esses novos produtos/tecnologias e suas funções, ou seja, conhecer suas utilidades, para que servem e que valores novos estão agregados a eles. Os lançamentos envolvem esse novo homem uma vez que, antigamente, ele não encontrava coisas específicas para homem como observamos abaixo:

Produtos específicos para homens, produtos só para homens, tinha uma cartela de produtos para homens e uma cartela de produtos para mulheres. Antes você via uma cartela de produtos para mulheres, se você quisesse você perguntava, que eu já, há uns cinco anos atrás, quando eu fui nessa mesma dermatologista, não existia, tinha pra mulher, e eu perguntei pra ela se existia esse tratamento, no caso era o botox, eu não precisava na época, mas eu já tava interessado em saber se existia pra homens, e me parece, pelo que ela me informou, é diferenciado o tratamento do botox para homem e para mulher, não é mesma coisa, então..., é como..., é...o shampoo de um homem é diferente do shampoo da mulher, o creme do homem certamente será diferente do creme da mulher, então, é isso, é o...(gagueja) o mercado se voltando e se...harmonizando com essa nova tendência, que é mundial, do homem se cuidar, do homem se...melhorar a todo tempo. (E5- L. 159-170)

Como podemos perceber, a indústria hoje lança produtos específicos para o público masculino, e o metrossexual procura manter-se informado em relação a isso, pois a busca por esses produtos/tecnologias, a partir do que foi falado acima, já ocorria, mas existia uma lacuna na indústria, ou seja, havia a demanda, mas não existia os produtos para suprimir essa necessidade. É o que Kotler (2000) chama de demanda latente, através da qual os consumidores desejam algo que não está disponível no mercado.

Assim, o metrossexual, procura manter-se informado sobre essas novidades, pois agora sabe que a indústria está se especializando nesse novo segmento, o homem, como segue:

(...) hoje já tem o outro lado, já tem na verdade uma linha muito mais específica, já tem um creme anti-rugas já tem na verdade uma série de coisa anti-brilho e outros fatores e outros produtos que já tão saindo pra isso é... a natura tem linha voltada só pra homem, a Avon tem linha voltada só pra homem, a própria Johnson também tem linha só pra homem, não só aqui no Brasil, mas fora também tem, a L'oreal também ela tem, eu passei um tempo fora, um mês fora para um intercâmbio de inglês no Canadá e lá tem uma linha que é específica só pra homem, na verdade assim, uma linha de limpeza, tratamento de pele e tudo. (E8- L.71-78)

Assim, a partir do trecho acima, observamos que as grandes marcas investem nesse novo segmento, e procuram suprir a demanda existente, além de estimular esse novo público a consumir, uma vez que disponibiliza novidades constantes no mercado. 
Não só novos produtos surgem no mercado, mas novas tecnologias, e o metrossexual conhece sobre isso, procura manter-se sempre informado, como dito abaixo:

(...) tem a questão do bronzeamento artificial, e a cirurgia também que eles chamam agora que é a de... você injeta um liquido no músculo e ele... ele... ele congela o músculo naquela tensão, bioplastia, e o que acontece...só que assim muitos médicos ainda não tão aprovando porque ainda é muito recente isso aí, não sabe o que vai acontecer no organismo daqui a 10 - 20 anos. (E8 - L.327-331)

A indústria tem investido fortemente nesse segmento, como podemos constatar a partir do trecho acima. Os homens buscam novidades, pois para eles a aparência é fundamental, e a indústria tendo percebido isso, começa a disponibilizar várias opções de serviços para satisfazer esse novo público, como vimos acima, bronzeamento artificial, procedimentos cirúrgicos exclusivamente voltados para atender as necessidades masculinas, entre outros serviços.

\section{Técnicas de cuidados}

A busca constante por uma aparência bonita leva o metrossexual a querer conhecer os efeitos dos produtos, ou ainda, a procurar se informar como esses produtos agem e devem ser usados, por exemplo:

É diário, tem cremes que não podem ser todos os dias, é alternado, segunda, quarta e sexta e domingo, aí eu tenho que saber essa tabela kkk, e tem outros não, que são para todos os dias, antes de passar o creme, além de lavar o rosto tem aquela... é... uma loção que remove as impurezas, então passa essa loção e aplica esses cremes. (E1- L.83-86)

A partir da primeira linha do trecho acima, observamos que esse novo homem cuida de si com seriedade, ele procura se informar sobre como usar determinado produto, e segue as recomendações. Ao ser dito no discurso acima "tem que saber essa tabela" e "então passa a loção e aplica a esses cremes", vemos que o metrossexual sabe a frequiência e ordem de usar determinado produto, mostrando que conhece a técnica, ou seja, não usa simplesmente por usar, mas procura alcançar os efeitos do produto o usando de forma adequada.

Até pouco tempo atrás o homem parecia não se importar com os cuidados voltados para a aparência, tomar um banho era o suficiente para ele. Hoje, a vaidade, o gostar de cuidar de si, faz com ele queira conhecer técnicas que aprimoram os cuidados, que o deixe mais bonito, como abaixo:

(...) limpeza de pele de 15 em 15 dia ( sic), massagem no rosto, sempre é bom é... massagear o rosto (...) muito bom. (...) É bom porque estimula as células...as células... (...) estimula pra criar novas células, tira as mortas e a massagem estimula, estimula... e com creme ajuda a... a penetrar melhor né, o creme. (E2- L338-340)

O metrossexual domina determinados conhecimentos que antes interessavam apenas a mulher. Falar de "células mortas", como no discurso acima, não fazia parte do discurso masculino, hoje, no entanto, ele já conhece e valoriza uma limpeza de pele, por exemplo, e conhece a importância de fazê-la. 


\subsection{Influência externa}

Diz respeito a como o meio externo influência nas opiniões e decisões das pessoas. $\mathrm{O}$ metrossexual compartilha dessa influência externa, uma vez que ele gosta de seguir as tendências e costuma incorporar ao seu dia-a-dia o que é exibido na mídia. Essa subcategoria incorpora dois elementos cuja discussão a respeito deles nos faz compreender melhor essa subcategoria, são eles: mídia e imagem de marca.

\section{Mídia}

A mídia é considerada como uma influenciadora de opinião e decisão. De acordo com Lima (2001), grande parte da sociedade contemporânea está centrada na mídia para, a partir dela, construir conhecimento e tomar decisões. A família, escola, igreja, partidos, entre outros, deixam de ser os grupos de referência, e a mídia passa a ser a grande influenciadora.

Para o metrossexual a mídia aponta para os padrões de beleza, aparência, e para ele esses são assuntos que o interessa, como visto a seguir:

Sim, eu acho que é o fator que pesa mais é a mídia... eu acho se... é aquela coisa se a gente não conhece determinada... determinada coisa ninguém vai querer ter, entendeu se eu não conhece... se eu nunca ouvi falar de Londres, eu não posso querer ir a Londres, porque... porque eu nunca ouvi falar de Londres, entendeu... então se o padrão fosse outro... se todo mundo seguisse outro padrão, ninguém ia achar estranho aquele padrão que se segue, é o que o que tá acontecendo hoje é que, eu acho que talvez o padrão de beleza imposto hoje não é o padrão normal entendeu, acho que naturalmente as pessoas tem um peso a mais e... tem algumas coisas que não gostam mais é saudável num tá no seu peso ideal, tá um pouco abaixo do peso, isso num é saudável, tá acima um pouco acima do peso, não muito obviamente, é que é saudável, aquelas coisas que com o tempo vão surgindo entendeu, mas eu acho que a imposição da mídia que aquele modelo que se criou que aquele modelo que se deve seguir é o que... o que guia essas coisas da vaidade. (E7- L.334-345)

A mídia desperta a aquisição de determinados conhecimentos e faz com que o metrossexual incorpore e assuma os padrões ditados por ela, como é ressaltado nas primeiras e ultimas linhas do trecho acima. Essa "imposição" citada é o que direciona o metrossexual a conhecer o que é bonito, o que está no padrão, e ele gosta de seguir isso.

As celebridades também servem como grupo de referência, ou seja, são modelos a serem seguidos. Como afirma Schiffman e Kanuk (2000, p. 234) "as celebridades representam idealização da vida que a maioria das pessoas imagina que gostaria de viver". Assim, o metrossexual está atento a mídia e as celebridades expostas nela, como segue:

Eu tento ler revistas, sempre que passa algum programa de TV paro um pouquinho dou uma olhada, vejo quais são as próximas tendências, se é uma camisa mais de uma cor, se é um sapato mais bico fino, bico quadrado, ou... hoje em dia pode ser tênis né muita gente usa tênis pra sair... é... (...) Exatamente, eu tento sempre tá antenado e no que possível adquirir esses produtos, me sentir bem, essas coisas. (...) Se eu não me engano tem a Caras, sempre tem fotos de...de artistas e normalmente essas pessoas seguem muito a moda e é bom sempre da uma olhada vê como eles tão se vestindo você pode aproveitar alguma coisa daquilo no seu dia a dia. (E10-L.62-74) 
No final do trecho acima, observamos a importância que as celebridades têm como referência para o metrossexual. Ele acredita que essas pessoas "seguem muito a moda", ou seja, são pessoas antenadas, que conhecem e estão em dia com sua aparência. Dessa forma, o metrossexual procura se espelhar nelas.

Assim, as empresas sabem da importância da mídia atualmente para a sociedade, e se utiliza dela para alcançar seus objetivos, para influenciar decisões de consumo e moda que devem ser seguidas, como observamos abaixo:

Com certeza, muitas vezes, a mídia ela... ela leva você a uma tendência pra moda, a aquele tipo de roupa, tá se preocupando mais com uma determinada coisa, um artigo, é... por exemplo é... hoje em dia tem... tem muitas abordagens sobre desfile de moda... na mídia mesmo, local onde tem desfile é aquela repercussão, passa na TV, no jornal, eu creio que isso é pra chamar o público pra ter um consumo maior dos artigos, e seguir essa moda que... hoje em dia tantos correm atrás. (E10- L.83-86)

Tendo em vista que a mídia dita os padrões de moda, as empresas se utilizam dela para lançar e vender seus produtos. E a partir disso, o metrossexual busca se informar, como citado no trecho acima.

\section{Imagem de marca}

O metrossexual atribui valor às marcas, seja porque acredita que estas garantam mais qualidade, seja porque tragam status. Para Schiffman e Kanuk (2000, p. 129) "imagem positiva de marca está associada a fidelidade do consumidor, crenças do consumidor acerca de valores positivos da marca e um desejo de procurar a marca", o discurso abaixo comenta sobre isso:

Eu acho que o essencial é o estilo que a pessoa impõe ao vestir, só que, eu, por exemplo, dou muito valor a marca, né, eu gosto muito de marca nem sempre eu posso comprar marca, porque são caras mas eu gosto muito; né, eu acho que... a marca ela dá um valor extra a roupa, não quer dizer que ela seja fundamental não, eu conheço muitas pessoas que se vestem muito bem... independente de marca, eu creio que uma... uma grife quando lança uma coleção, ela tá lançando o que tem de mais moderno, né que tem tendência, você não vai comprar uma roupa cara ela estando ultrapassada, então ela é tendência, então, se é uma grife conhecida, provavelmente o que ela tá colocando ali, expondo é coisa muito... atual, eu penso dessa forma, mas nem sempre a marca quer dizer muita coisa, têm pessoas que não ligam pra marca, pegam uma coisa de um jeito, outra coisa...e monta um visual super legal independente de... de marca, a marca também da um pouco de status né, você vê lá, ah essa roupa foi cara e tem gente que pega roupa caríssima e não sabe se vestir, então você não vai comprar em uma loja grande de marca e sabe que tem uma série pessoas por trás daquilo... estilista, é... modista que tá botando coisas... atuais, você tá usando coisas boas... caras e boas. (E9- L.49-69)

Como afirma Churchill (2003, p. 245) "as marcas podem reduzir o tempo e a energia envolvidos no processo de compra, além de proporcionar bons sentimentos derivados de associações positivas com a marca". Essa afirmação do autor se comprova no trecho acima, no qual observamos que para o entrevistado a marca é uma garantia de que o produto é bom, atual, na moda, ou seja, ele confia, por isso se sente seguro em adquiri-lo, e provavelmente não perde tempo pensando em qual marca levar, pois ele já conhece a que gosta. Assim, 
como refletido no início do trecho, o metrossexual exalta a marca, mesmo tendo que pagar mais caro por uma peça de marca, porque acredita no valor que ela apresenta. Esse valor é aceito por ele acreditar que uma grife, por exemplo, "lança o que tem de mais moderno", assim, ele se sente seguro porque "está usando coisas boas", como é ressaltado no final da fala acima.

Outro aspecto retratado no discurso acima é que apesar da importância da marca e o metrossexual valorizá-la, ele afirma que ela não é essencial. O que aparece também abaixo

(...) hoje em dia eu acho que tem várias formas, não só a questão da roupa, da marca, do que está na moda, ou às vezes, apenas uma etiqueta. Eu não me importo tanto com a etiqueta né, não, pra mim, eu acho que muitos ainda sim, mas com roupas mais adequadas. (E1- L42-45)

Apesar dos trechos acima falarem sobre não se importar com a marca, observamos que ela é importante sim, pois mesmo estando presente no discurso a negação dessa importância, temos a comprovação de que ela agrega valores, como vemos a seguir:

Não importante, mas tem algumas marcas que...além da qualidade ela tem um caimento muito bom pra um determinado tipo de pessoa, que como eu falei algumas marcas ela tem um corte mais largo ou mais fino nas pernas, uma camisa pode ser também ou mais larga ou mais comprida e dependendo do tipo físico da pessoa se encaixa melhor. (E10- L.54-57)

Por valorizar a marca, o preço de determinadas marcas não interfere na compra do metrossexual. Como afirma Churchill (2003, p. 245) "usar uma marca é uma maneira de distinguir produtos na mente de compradores potenciais. Eles podem dedicar um esforço extra e gastar dinheiro adicional para comprar uma determinada marca". Acreditamos que isso ocorre porque ele paga pelo valor agregado ao produto, como no trecho a seguir:

É, eu gosto de... eu me preocupo também assim...eu gosto de usar sempre uma marca, que geralmente tem marca que veste bem, tem marca que não veste, sabe. Tendo uma marca que não veste bem, e se eu ver que a...a roupa que ela produz se vestir bem, aí eu vou pela marca também. (...) É, independendo do valor. Isso aí dá um jeito. (...) Se...é...o importante pra mim é se sentir bem né, você se realizando, tando, tá se sentindo bem, não importa o valor. O que vale é você ta com auto-estimo né, se achando elegante...é isso. (E11- L.203-213)

Assim, observamos que mesmo os entrevistados afirmando nos seus discursos que a marca não é fundamental, vemos que, em todos eles, o discurso se contradiz, ressaltando que a marca é valorizada, e se adquiri produtos de marca "independente do valor", como citado no meio do trecho acima.

\section{CONSIDERAÇÕES FINAIS}

A pesquisa ora apresentada pretende contribuir para a construção de um conhecimento hoje insipiente: o consumidor metrossexual. Neste sentido, os resultados aqui apresentados evidenciam a importância do consumo para a formação identitária destes sujeitos. O que nossos achados parecem nos demonstrar a este respeito se refere ao dilema em que os metrossexuais se encontram. Se, por um lado, seus comportamentos são fidedignos do contemporâneo, por outro, ainda existem barreiras sociais que os controlam. Nossas duas 
dimensões apontam neste sentido. Ao mesmo tempo em que o comportamento metrossexual demonstra uma busca de construção da imagem pessoal para o outro, se detém à avaliação que este outro fará. Neste aspecto, vemos uma luta entre o preconceito e a busca de apoio; em relação à imagem pessoal, uma busca de auto-expressão, mas também de ganhos por meio desta. Incoerência? Talvez, sim. Mas certamente um tipo de "incoerência" pertinente à própria condição da subjetividade na pós-modernidade (Elliott, 1997; Firat e Shultz II, 1997; Firat et al., 1995).

Do ponto de vista teórico, deparamo-nos, pois, com o desafio de dar início à busca de uma construção teórica que forneça os subsídios necessários à compreensão deste comportamento cultural refletido numa nova identidade, que, antes, parece guardar uma característica fundamental das sociedades pós-modernas: a constituição identitária por meio do consumo.

Para a Administração de Marketing, entendemos tratar-se de uma lacuna de conhecimento a ser preenchida, uma vez que o metrossexual demonstra um grande potencial de consumo. Nossa pesquisa parece apontar a possibilidade de se fazer uma abordagem que busque não apenas o próprio sujeito metrossexual, mas sua rede social, como forma de, por meio desta, legitimar seu comportamento de consumo.

Entendemos que a presente pesquisa seja apenas um dos primeiros passos conhecidos nos direcionamentos aqui propostos. Pesquisas realizadas em outras localidades ou em outras culturas podem ampliar o escopo de entendimento do fenômeno. A utilização de outros métodos, como a etnografia, por exemplo, podem, por sua vez, possibilitar que aspectos não explicitados numa abordagem direta, como é o caso das entrevistas, sejam desvelados.

\section{REFERÊNCIAS}

BAUDRILLARD, J. A sociedade de consumo. Lisboa: Edições 70, 2003.

BAUMAN, Z. Identidade. São Paulo: Jorge Zahar Ed., 2005.

BRANDÃO, H. Introdução à análise do discurso. 5.ed. Campinas: UNICAMP, 1997.

CAMPBELL, C. Eu compro, logo sei que existo: as bases metafísicas do consumo moderno. In: BARBOSA, L.; CAMPBELL, C. (Orgs.). Cultura, consumo e identidade. Rio de Janeiro: Editora FGV, 2006.

CECCHETTO, F. R. Violência e estilo de masculinidade. Rio de Janeiro: Editora FGV, 2004.

FILHO, C. B; LOPES. F.; e CARASCOZA, J. Identidade e consumo na pós-modernidade: crise e revolução no marketing. FAMECOS. Porto Alegre, vol. 1(31), dez. 2006.

FIRAT, A. F. The consumer in postmodernity. Advances in Consumer Research, 18(1), pp.70-76, 1991.

FOUCAULT, M. A Arqueologia do saber. Rio de Janeiro. Forense Universitária, 2002.

FOUCAULT, Michel. A Ordem do Discurso. São Paulo: Edições Loyola, 1996. 
GARCIA, W. O corpo contemporâneo: a imagem do metrossexual no Brasil. Mneme Revista Virtual de Humanidades, v.5 (11), pp. 184-198, set. 2004.

HALL, S. A identidade cultural na pós-modernidade. 10.ed. Rio de Janeiro: DP\&A, 2005.

KACEN, J. J. Girrrl power and boyyy nature: the past, present, and paradisal future of consumer gender identity. Marketing Intelligence \& Planning, v.18(6), pp. 345-355, 2000.

LEÃO, A. L. M. S.; MELLO, S. C. B. "Valor de marca" para quem? - Rumo a uma teoria da significação das marcas pelos consumidores. XXXI EnANPAD. Anais... Rio de Janeiro, 2007.

LOURO, G. L. Pedagogias da sexualidade. In: Louro, G. L. (Org.). O corpo educado: pedagogias da sexualidade. Belo Horizonte: Autêntica, 1999.

MITTALL. B.; HOLBROOK, M.; BEATTY, S. Consumer behavior: how humans think, feel and act in the marketplace. Cincinatti, OH: Open Mantis, 2008.

ORTIZ, R. Mundialização e cultura. São Paulo: Brasiliense, 2003.

PÊCHEUX, M. O discurso: estrutura ou acontecimento. Campinas: Pontes, 2002.

OLIVEIRA, P. P. A construção social da masculinidade. Belo Horizonte: Editora UFMG, 2004.

PINHO, O. Qual é a identidade do homem negro? In: Democracia Viva, n. 22, 2004.

SILVA, T. T. A produção social da identidade e diferença. In: SILVA, T. T. (org). Identidade e diferença: a perspectiva dos estudos culturais. Petrópolis: Vozes, 2000.

SIMPSOM, M. Here come the mirror men. The Independent, nov. 1994.

. Meet the metrossexual. Revista online Salon, Jul. 2002.

SLATER, D. Cultura do consumo \& modernidade. São Paulo: Nobel, 2002.

WOODWARD, K. Identidade e diferença: uma introdução teórica e conceitual. In: SILVA, T. T. (org). Identidade e diferença: a perspectiva dos estudos culturais. Petrópolis: Vozes, 2000 . 